\title{
PURIFICAÇÃO E ISOENZIMAS DA LACTATO DESIDROGENASE DO MÚSCULO EPAXIAL DE Prochilodus scropha e Notothenia neglecta*.
}

\section{CLEONI SANTOS CARVALHO ${ }^{1}$; RUBENS ROSA ${ }^{2}$; KIKUE T. SASSAKI; METRY BACILA ${ }^{1}$}

\author{
Estação Antártica Brasileira Comandante Ferraz, Ilha do Rei Jorge, Shetlands do Sul. \\ ${ }^{1}$ Curso de Pós-Graduação em Ciências Veterinárias e Laboratório de Piscicultura da Universidade Federal do Paraná, \\ CEP 80.000-970, Curitiba-Pr-Brasil. ${ }^{2}$ Departamento de Medicina, Pontifícia Universidade Católica do Paraná - PUC-PR.
}

\begin{abstract}
It has been carried out a comparative study on the purification of the lactate dehydrogenase (Llactate $\mathrm{NAD}^{+}$oxidoreductase, E.C.1.1.1.27) from the epaxial muscle of the tropical fish Prochilodus scropha and the Antarctic fish Notothenia neglecta. Purification of LDH from both sources was carried out by oxamateagarose affinity chromatography. The eletrophorectic profile in cellulose acetate showed a single band in both preparations. However it has been observed that in barbital buffer $\mathrm{pH}$ 8.6, the LDH from P. scropha migrates towards the cathode while the LDH from $N$. neglecta, migrates towards the anode.
\end{abstract}

Key Words: Lactate dehydrogenase; Prochilodus scropha; Notothenia neglecta.

RESUMO - Foi levado a efeito um estudo comparativo de purificação da lactico desidrogenase (L-lactato NAD ${ }^{+}$ oxidorreductase, E.C.1.1.1.27) do músuclo epaxial do peixe tropical Prochilodus scropha e do peixe antártico Notothenia neglecta. A purificação da LDH de ambas as fontes foi procedida por cromatografia de afinidade em oxamato-agarose, tendo revelado uma única banda de proteína em eletroforese em acetato de celulose, para ambas as preparações. Contudo, foi verificado que em eletroforese em tampão barbital pH 8,6, a LDH de $P$. scropha migra para o cátodo enquanto que a de $N$. neglecta migra para o ânodo.

Palavras-Chave: Lactato desidrogenase; Prochilodus scropha; Notothenia neglecta.

\section{Introdução}

A láctico desidrogenase (LDH) (L-Lactato: NADH oxidorredutase, E.C.1.1.1.27), é de fundamental importância em processos envolvendo o metabolismo glicídico. Essa enzima catalisa a transformação reversível do lactato para piruvato, com suporte coenzimático do sistema $\mathrm{NAD}^{+} / \mathrm{NADH}+\mathrm{H}^{+}$. É essencial para o suprimento de $\mathrm{NAD}^{+}$para a reação da gliceraldeído-fosfato desidrogenase, direcionando dessa forma a finalização aeróbica ou anaeróbica da via glicolítica, frente às necessidades metabólicas do tecido.

A LDH é um tetrâmero de PM 140.000. Cada subunidade liga-se a uma molécula de coenzima e reage independentemente com o substrato (HECK,1969). Dois tipos de subunidades estão presentes na proteína oligomérica de LDH e o padrão isoenzimático está relacionado com o tipo de metabolismo de cada tecido: o tipo H (coração) e o tipo $\mathrm{M}$ (músculo), de acordo com os órgãos em que foram obtidos (DAWSON et al., 1964). O tipo $\mathrm{H}$ (ou tipo B) predomina em tecidos de metabolismo aeróbico, tal como o músculo cardíaco. É composta de 4 subunidades $\left(\mathrm{H}_{4}\right)$, sendo inibida por altas concentrações de piruvato (dentro

\footnotetext{
*Com base na Tese de Mestrado de Cleoni Santos Carvalho, Curso de Pós-Graduação em Ciências Veterinárias, UFPR.

Com auxílio da Programa Antártico Brasileiro - PROANTARCNPq. ${ }^{1}$ Bolsista de Pós-Graduação do CNPq.
}

de uma taxa fisiológica) e com baixo $\mathrm{K}_{\mathrm{M}}$ para este substrato. $\mathrm{O}$ tipo $\mathrm{M}$ (ou tipo $\mathrm{A}$ ) predomina em tecidos como o músculo esquelético, o qual deriva grande parte de sua energia da glicólise anaeróbica. A isoenzima do músculo esquelético está adaptada para converter altas concentrações de piruvato a lactato apresentando alto $K_{M}$ e Vmax elevado para o piruvato (SIDELL e BELAND, 1980).

A LDH tem sido purificada de várias fontes, tanto de animais como de vegetais, e muitos procedimentos para o isolamento da enzima foram utilizados. STRAUB (1940) purificou pela primeira vez a LDH de coração de bovino. A metodologia utilizada consistia em adsorção da enzima por fosfato de cálcio, eluições e várias etapas de precipitação com sulfato de amônio e acetona. O método amplamente utilizado na purificação da enzima durante os últimos 20 anos tem sido a cromatografia de troca iônica, com dietilaminoetilcelulose (DEAE), carboximetil-celulose (CMC) e fosfocelulose (PC) (SCOPES, 1981).

Eluição por afinidade em cromatografia de troca iônica envolve a eluição de enzimas (ou outro ligante específico) por inclusão de um substrato ou ligante específico no tampão de eluição. Um ligante com carga liga-se à molécula de proteína reduzindo a carga total e então decrescendo a interação da proteína com o trocador iônico. Portanto, o ligante deve ter a mesma carga de trocador iônico, oposta à proteína a que vai ligar-se.

Lactato desidrogenase existe numa variedade de 
formas isoenzimáticas, $\mathrm{H}_{4}, \mathrm{H}_{3} \mathrm{M}_{1}, \mathrm{H}_{2} \mathrm{M}_{2}, \mathrm{H}_{1} \mathrm{M}_{3}$ e $\mathrm{M}_{4}$. Essas formas isoenzimáticas são separadas por eletroforese em acetato de celulose e podem ser subsequentemente visualizadas em 5 bandas distintas por uma reação de coloração específica.

As isoenzimas $\mathrm{H}$ e $\mathrm{M}$ são similares no peso molecular mas diferem grandemente em propriedades físicas, químicas e imunológicas, como também nas propriedades catalíticas e em sua distribuição nos tecidos (VESELL, 1966; VESELL e YIELDING, 1966 e BAILEY e WILSON, 1968). Em mamíferos e aves, e em alguns peixes teleósteos, existe um terceiro tipo de $\mathrm{LDH}$, denominado de LDH X ou isoenzima C. Em peixes, ela é encontrada no fígado (REHSE e DAVIDSON, 1985), no cérebro e no olho (FITCH, 1988, COPPES et al., 1992), e em ratos, no espermatócito (SPIELMANN et al., 1973).

Peixes da família Notothenidae são abundantes e amplamente distribuídos nos mares antárticos, sendo o grupo de peixes mais diversificado em relação à espécie, habitat e distribuição. Evidências sugerem que espécies de peixes Antárticos tornaram-se isolados pela convergência circumpolar Antártica durante o Período Terciário e têm evoluído independentemente de outros grupos de teleósteos sob pressão seletiva de glaciações sucessivas desde aquele tempo (De WITT, 1971).

O presente trabalho (CARVALHO, 1997) descreve a purificação da LDH do músculo estriado branco de Notothenia neglecta e de curimbatá, Prochilodus scropha, além de verificar a presença de formas múltiplas da enzima que determinam o seu padrão isoenzimático. De outro lado, intenta-se com o presente trabalho fazer um estudo comparativo entre as propriedades da $\mathrm{LDH}$ de músculo estriado de peixes adaptados às condições ambientais do Continente Antártico e de peixes da região tropical.

\section{Material e Métodos}

A LDH foi obtida e purificada a partir de músculo estriado branco de exemplares de Prochilodus scropha, curimbatá, capturados no Centro de Cultivo de Peixes do IBAMA, Pirassununga, São Paulo. Peixes adultos foram levados para o laboratório do Centro de Cultivo, onde foram sacrificados por secção da coluna vertebral. A seguir, os tecidos musculares estriados foram dissecados, lavados em solução fisiológica a $4^{0} \mathrm{C}$, armazenados e mantidos a $4^{0} \mathrm{C}$, e transportados para o Instituto de Química da Universidade de São Paulo, em isopor contendo gelo seco. O material biológico de Notothenia neglecta foi obtido durante a Operação Verão da XIV Expedição Antártica Brasileira. Peixes adultos foram levados para o Laboratório da Estação, onde foram sacrificados por secção da coluna vertebral. A seguir, os tecidos musculares estriados foram dissecados, lavados em solução fisiológica a $4^{0} \mathrm{C}$, armazenados e mantidos a $4^{0} \mathrm{C}$, e transportados para os nossos laboratórios em isopor contendo gelo seco.

Substratos, coenzimas, lactato desidrogenase e outros produtos químicos foram obtidos da Sigma Chemical Co., St. Louis, MO, USA e produtos inorgânicos utilizados foram todos pró-análise.

A LDH do extrato bruto, foi purificada por cromatografia de afinidade em oxamato-agarose. A cromatografia foi executada segundo o método de O'CARRA e BARRY, 1972. A resina de oxamatoagarose foi transferida para coluna de vidro de $0,7 \mathrm{x}$ $10,0 \mathrm{~cm}$ e lavada em tampão fosfato de potássio 0,02 $\mathrm{M}, \mathrm{pH}$ 6,8 contendo $\mathrm{NaCl} 0,5 \mathrm{M}$, equilibrada em tampão fosfato de potássio $0,02 \mathrm{M}, \mathrm{pH} 6,8$ contendo $\mathrm{NaCl} 0,5 \mathrm{M}$ e $\mathrm{NADH}+\mathrm{H}^{+} 0,2 \mathrm{mM}$. Cerca de cinco gramas de músculo estriado congelado, para ambas as espécies, foram lavados em solução salina $0,9 \%$ e ressuspensos em tampão fosfato $0,02 \mathrm{M}, \mathrm{pH} 6.8$, contendo $\mathrm{NaCl}$ 0,5 M. Os tecidos foram homogeneizados em tampão fosfato de potássio 0,02 M, pH 6.8, contendo $\mathrm{NaCl} \mathrm{0,5} \mathrm{M,} \mathrm{na} \mathrm{proporção} \mathrm{de} \mathrm{1:4}$ de tampão em homogeneizador do tipo PotterElvehjem. Os homogeneizados foram centrifugados em centrífuga refrigerada $\mathrm{K} 70 \mathrm{D}, 4^{0} \mathrm{C}$, a $10.000 \mathrm{rpm}$, durante 30 minutos. Os sedimentos foram desprezados; os sobrenadantes, constituindo o extrato bruto (EB), foram utilizados como fonte de enzima. Alíquotas de 3,0 $\mathrm{ml}$ do extrato bruto, de ambas preparações, foram adicionadas de $\mathrm{NaCl} 0,5 \mathrm{M}$ e $\mathrm{NADH}+\mathrm{H}^{+}$0,2 mM, pH 6,8 e adicionadas à coluna de oxamato-agarose. O fluxo foi ajustado para 1,0 $\mathrm{ml} / 20$ minutos. Após a fixação da enzima, a coluna foi lavada com tampão fosfato de potássio $0,02 \mathrm{M}, \mathrm{pH}$ 6,8 contendo $\mathrm{NaCl} 0,5 \mathrm{M}$ e $\mathrm{NADH}+\mathrm{H}^{+} 0,2 \mathrm{mM}$ até que a leitura de absorbância a $280 \mathrm{~nm}$ não mais indicasse a presença de proteína. A enzima foi eluída com o mesmo tampão, na ausência de $\mathrm{NADH}+\mathrm{H}^{+}$. As frações coletadas foram então analisadas quanto à atividade de LDH e concentração de proteína. A separação das formas isoenzimáticas da $\mathrm{LDH}$ foi realizada através da eletroforese em acetato de celulose, utilizando-se o extrato bruto de músculo estriado branco de Prochilodus scropha e de Notothenia neglecta obtidos como foi descrito. O método empregado foi o descrito por BARNETT, 1962, usando-se tampão barbital de sódio 0,04 M, pH 8,6 e fitas de acetato de celulose $(2,5 \times 14 \mathrm{~cm})$ a $200 \mathrm{~V}$, $23 \mathrm{~mA}$, durante 2 horas a $4^{0} \mathrm{C}$. As fitas foram reveladas sobre camada de ionagar $5 \mathrm{mg} / \mathrm{ml}$ solidificada em placa de vidro, contendo lactato de lítio $0,1 \mathrm{M}, \mathrm{NAD}^{+} 1,5 \mathrm{mM}$, NBT $0,4 \mathrm{mM}$, PMS $0,1 \mathrm{mM}$, em estufa a $37^{\circ} \mathrm{C}$, durante 40 minutos na ausência de luz. Após a revelação, as fitas foram desidratadas em metanol puro e diafanizadas em solução contendo metanol $85 \%$, ácido acético glacial $14 \%$ e glicerol $1 \%$.

A atividade da $\mathrm{LDH}$ foi medida em meio contendo 
$\mathrm{NADH}+\mathrm{H}^{+} 0,14 \mathrm{mM}$ e piruvato de sódio $1 \mathrm{mM}$, em tampão fosfato de sódio $0,1 \mathrm{M}, \mathrm{pH} 7,4$, em volume final de $1,0 \mathrm{ml}$, segundo BERGMEYER e BERN, 1974. A velocidade de oxidação do $\mathrm{NADH}+\mathrm{H}^{+}$foi acompanhada em espectrofotômetro BECKMAN DU 640, em comprimento de onda de $340 \mathrm{~nm}$ e à temperatura de $25^{\circ} \mathrm{C}$ para Prochilodus scropha e entre $8,0 \pm 2,0^{\circ} \mathrm{C}$ para Notothenia neglecta.

Uma unidade (UI) de LDH é definida como a quantidade de enzima que catalisa a transformação de $1 \mu \mathrm{m}$ de piruvato ou de lactato por minuto, nas condições de ensaio especificadas. A atividade específica é expressa em UI/mg de proteína.
A concentração de proteína foi determinada pelo método de LOWRY et al., (1951), utilizandose como padrão protéico a albumina sérica bovina.

\section{Resultados}

A LDH de Prochilodus scropha e de Notothenia neglecta foi extraída e purificada por cromatografia de afinidade em coluna de oxamato-agarose. Os dados são mostrados nas Tab. 1 e 2 . Os perfis cromatográficos de eluição em oxamato-agarose da LDH de Prochilodus scropha e de Notothenia neglecta são mostrados nas Fig. 1 e 2.

Tabela 1. Extração e purificação de LDH de músculo estriado de Prochilodus scropha em oxamato-agarose.

\begin{tabular}{lcccccc}
\hline AMOSTRA & $\begin{array}{c}\text { Proteína } \\
(\mathrm{mg} / \mathrm{ml})\end{array}$ & $\begin{array}{c}\text { Volume } \\
(\mathrm{ml})\end{array}$ & $\begin{array}{c}\text { Atividade } \\
(\mathrm{UI} / \mathrm{ml})\end{array}$ & $\begin{array}{c}\text { Atividade } \\
\text { especifica } \\
\text { (UI/mg } \\
\text { de proteina) }\end{array}$ & $\begin{array}{c}\text { Rendimento } \\
(\%)\end{array}$ & $\begin{array}{c}\text { Purificação } \\
(\mathrm{O})\end{array}$ \\
\hline Extrato Bruto & 20,77 & 1,00 & 503,38 & 24,33 & 100,00 & 1,00 \\
$\begin{array}{l}\text { Eluato da coluna de } \\
\text { oxamato-agarose }\end{array}$ & 0,06 & 1,00 & 227,33 & 3726,72 & 45,16 & 153,80 \\
\hline
\end{tabular}

Tabela 2. Extração e purificação de LDH de músculo estriado de Notothenia neglecta em oxamato-agarose.

\begin{tabular}{lcccccc}
\hline AMOSTRA & $\begin{array}{c}\text { Proteina } \\
(\mathrm{mg} / \mathrm{ml})\end{array}$ & $\begin{array}{c}\text { Volume } \\
(\mathrm{ml})\end{array}$ & $\begin{array}{c}\text { Atividade } \\
(\mathrm{UI} / \mathrm{ml})\end{array}$ & $\begin{array}{c}\text { Atividade } \\
\text { específica } \\
\text { (UI/mg } \\
\text { de proteina })\end{array}$ & $\begin{array}{c}\text { Rendimento } \\
(\%)\end{array}$ & $\begin{array}{c}\text { Purificação } \\
(X)\end{array}$ \\
\hline Extrato Bruto & 33,30 & 1,00 & 113,99 & 3,42 & 100,00 & 1,00 \\
Eluato da coluna & 0,048 & 1,00 & 78,46 & 1651,79 & 68,83 & 482,98 \\
oxamato-agarose & & & & & \\
\hline
\end{tabular}

Fig 1. Perfil cromatográfico da lactato desidrogenase de músculo estriado de Prochilodus scropha em oxamato-agarose. A coluna de oxamato-agarose foi equilibrada com tampão fosfato $0,02 \mathrm{M}, \mathrm{pH} 6,8$, contendo $\mathrm{NaCl} 0,5 \mathrm{M}$ e $\mathrm{NADH}+\mathrm{H}^{+} 0,2 \mathrm{mM}$. O extrato bruto, adicionado de $\mathrm{NaCl} 0,5 \mathrm{M}$ e NADH$+\mathrm{H}^{+} 0,2 \mathrm{mM}$, contendo $20,77 \mathrm{mg} / \mathrm{ml}$ de proteína foi aplicado à coluna. A eluição foi levada a efeito no mesmo tampão sem $\mathrm{NADH}+\mathrm{H}^{+}$(A), acompanhada de leituras de absorbância a $280 \mathrm{~nm}$ e a atividade enzimática medida de acordo com o procedimento descrito em Métodos. 
A eletroforese em acetato de celulose revelou a presença da isoenzima LDH-4, correspondente à $\mathrm{M}_{4}\left(\mathrm{~A}_{4}\right)$, para o músculo esquelético branco de ambas as espécies. As isoenzimas da LDH de Prochilodus scropha e de Notothenia neglecta apresentaram perfil eletroforético distintos. A LDH-4 de Prochilodus scropha mostrou mobilidade eletroforética em direção ao cátodo e a LDH-4 de Notothenia neglecta mobilidade ao ânodo (Fig. 3).

Fig. 2. Perfil cromatográfico da lactato desidrogenase de músculo estriado de Notothenia neglecta em oxamato-agarose. A coluna de oxamato-agarose foi equilibrada com tampão fosfato $0,02 \mathrm{M}, \mathrm{pH} 6,8$, contendo $\mathrm{NaCl} 0,5 \mathrm{M}$ e $\mathrm{NADH}+\mathrm{H}^{+} 0,2 \mathrm{mM}$. O extrato bruto, adicionado de $\mathrm{NaCl} 0,5 \mathrm{M}$ e NADH$+\mathrm{H}^{+} 0,2 \mathrm{mM}$, contendo $33,298 \mathrm{mg} / \mathrm{ml}$ de proteína e aplicado à coluna. A eluição foi levada a efeito no mesmo tampão sem $\mathrm{NADH}+\mathrm{H}^{+}$(A), acompanhada de leituras de absorbância a $280 \mathrm{~nm}$ e a atividade enzimática medida de acordo com o procedimento descrito em Métodos.

\section{Discussão}

Vários trabalhos são relatados na literatura com enzimas da via glicolítica em peixes antárticos SOMERO e HOCHACHKA, 1968; LOW e SOMERO, 1976; FITCH, 1988; BACILA et al., 1989; FELLER et al., 1991 e ZAMORA et al., 1992. Entretanto, estudos bioquímicos em peixes antárticos, com relação a lactato desidrogenase, são limitados a poucos trabalhos (FITCH, 1988; BACILA et al., 1989 e FELLER et al., 1991).

BACILA et al. (1989), realizaram estudos sobre o metabolismo tecidual do "ice-fish" Chaenocephalus aceratus, estabelecendo os níveis das enzimas glicolíticas em músculo estriado, músculo cardíaco e encéfalo. Verificaram que o "ice-fish" possui níveis altos de PK, PFK, HK e em particular de LDH em todos os tecidos analizados. Estes mesmos autores verificaram que o "ice-fish" Chaenocephalus aceratus possui níveis dessas enzimas, inclusive os de LDH, superiores aos de outros peixes antárticos tais como Notothenia rossii e Notothenia neglecta.

Estes fatos mostram que um estudo mais aprofundado das enzimas da via glicolítica é de fundamental importância para melhor se entender o comportamento bioquímico e fisiológico desses animais. Como enzima diretamente ligada à via glicolítica a LDH foi utilizada, na presente pesquisa, purificada a partir do músculo estriado de Notothenia neglecta e de Prochilodus scropha.

O presente experimento mostra eluição de LDH em cromatografia por afinidade em oxamato-agarose. Oxamato é um análogo estrutural do piruvato contendo um grupo amida que corresponde ao grupo metil do piruvato, sendo um inibidor da LDH estritamente competitivo com o piruvato. Os resultados apresentados nas Tab. 1 e 2 mostram que na passagem do extrato bruto (EB) pela coluna de oxamato-agarose ocorre uma purificação de 153,80 vezes para LHD de Prochilodus scropha e de 482,98 vezes para LDH de Notothenia neglecta com recuperação de 45,16 e 68,83\%, respectivamente. Sendo o NADH $+\mathrm{H}^{+}$adicionado a amostras de LDH e ao tampão de eluição, a LDH é retida na coluna e continua adsorvida enquanto $\mathrm{NADH}+\mathrm{H}^{+}$é incluido no tampão de eluição, a l-LDH liga-se primeiro ao $\mathrm{NADH}+\mathrm{H}^{+}$, seguida do análogo ao piruvato. Tão logo o $\mathrm{NADH}+\mathrm{H}^{+}$foi omitido do tampão de eluição, a LDH foi eluida praticamente um volume da coluna depois (Fig. 1 e 2). Esses resultados são indicativos de um sítio de ligação para o análogo 
ao piruvato a qual é induzido na LDH na ligação do $\mathrm{NADH}+\mathrm{H}^{+}$, mas o qual está ausente na enzima livre (O'CARRA e BARRY, 1972). Esse comportamento da enzima torna o método duplamente específico, uma vez que a adsorção na oxamato-agarose seleciona a enzima na especificidade ao oxamato e na especificidade ao $\mathrm{NADH}+\mathrm{H}^{+}$. Esses valores confirmam a especificidade desta resina à $\mathrm{LDH}$, já descritos por O'CARRA e BARRY, 1972; O'CARRA e BARRY, 1974; FITCH, 1988; SASSAKI et al., 1994.

$$
\begin{aligned}
& \text { P.scropha } \\
& \text { N.neglecta } \\
& \text { Músculo de rato } \\
& \text { Fígado de rato } \\
& \text { (-)cátodo }
\end{aligned}
$$

Fig. 3. Perfil eletroforético de formas múltiplas da lactato desidrogenase de tecidos de rato comparadas com a lactato desidrogenase do músculo estriado de Prochilodus scropha e de Notothenia neglecta. Alíquotas de $10 \mu 1$ contendo 0,03-0,04 UI de enzimas por $\mathrm{ml} \mathrm{de} \mathrm{Prochilodus} \mathrm{scropha} \mathrm{e} \mathrm{Notothenia} \mathrm{neglecta} \mathrm{foram} \mathrm{aplicadas} \mathrm{em} \mathrm{fita} \mathrm{de} \mathrm{acetato} \mathrm{de} \mathrm{celulose} \mathrm{e} \mathrm{a}$ eletroforese levada a efeito a 200 volts, durante 2 horas, em tampão barbital de sódio, 0,04 M, pH 8,6. As fitas foram reveladas sobre camada de ionagar $5 \mathrm{mg} / \mathrm{ml}$ solidificada em placa de vidro, contendo lactato de lítio $0,1 \mathrm{M}, \mathrm{NAD}^{+} 1,5 \mathrm{mM}$, NBT $0,4 \mathrm{mM}$, PMS $0,1 \mathrm{mM}$, em estufa a $37^{\circ} \mathrm{C}$, durante 40 minutos. Após a revelação, as fitas foram desidratadas em metanol puro e diafanizadas em solução contendo metanol $85 \%$, ácido acético glacial $14 \%$ e glicerol $1 \%$.

GADE (1978), a partir do manto muscular de lula, Loligo vulgaris, ELLINGTON e LONG (1978), com músculo de craca gigante Balanus nubilus e THÉBAULT et al., (1981), com músculo caudal de camarão Palaemon serratus purificaram a LDH através de cromatografia de afinidade em Sephadex G-200. O primeiro obteve um aumento de purificação e atividade específica de 378 vezes; para ELLINGTON e LONG (1978), a purificação não resultou em aumento da atividade específica, mas removeu várias proteínas contaminantes e THÉBAULT et al., (1980) obtiveram um rendimento de $42 \%$ e purificação de 15 vezes.

Cromatografia de afinidade em Sepharose5'AMP para a purificação da LDH foi realizada por ELLINGTON e LONG (1978), os quais obtiveram uma purificação de 662 vezes e recuperação de $32 \%$, a partir do músculo de craca gigante Balanus nubilus; THÉBAULT et al., (1981), utilizando a mesma resina de afinidade, com músculo caudal de camarão Palaemon serratus, a purificação resultou em um aumento da atividade específica de cerca de 900 vezes e um rendimento de $13 \%$; ZIETARA e
SKORKOWSKI (1993), a partir de diferentes tecidos de bacalhau, Gadus morhua, utilizaram diferentes procedimentos para a purificação da

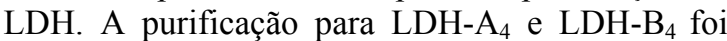
feita em músculo cardíaco para LDH-B $\mathrm{B}_{4}$ e músculo esquelético branco para $\mathrm{LDH}-\mathrm{A}_{4}$ e aplicação na coluna de afinidade oxamato-agarose. Para a obtenção da isoenzima LDH-B ${ }_{4}{ }^{\circ}$ o tecido utilizado foi o estômago de bacalhau. Este passou por várias resinas de purificação, cromatografia de troca iônica DEAE-celulose, Blue-agarose e cromatografia de afinidade Sepharose-5'AMP. Na $\mathrm{LDH}-\mathrm{C}_{4}$, o tecido utilizado foi o fígado, tendo sido aplicado em cromatografia DEAE-celulose e cromatografia de afinidade oxamato-agarose. A purificação das isoenzimas LDH dos tecidos foi de $96 \%$ e 45 vezes para $\mathrm{LDH}-\mathrm{A}_{4}, 21 \%$ e 35 vezes para

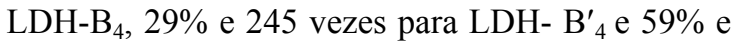
62 vezes para $\mathrm{LDH}-\mathrm{C}_{4}$.

FITCH (1988), purificou a LDH a partir do músculo de Notothenia neglecta e Myoxocephalus scorpius. Os tecidos foram aplicados em coluna de 
cromatografia de afinidade de oxamato-agarose, obtendo uma purificação de 6-13 vezes e um rendimento de 90\%; SASSAKI et al., (1994), purificaram a LDH de glândulas submandibulares de rato, Rattus novegicus albino em cromatografia de afinidade de oxamato-agarose e obtiveram uma recuperação de $65 \%$ e purificação de 540 vezes.

SASAKI et al., (1989) e SASSAKI et al., (1994), utilizaram para purificação de isoenzimas $\mathrm{LDH}_{-\mathrm{A}_{4}}$ e LDH-B 4 , cromatografia de afinidade em Blue-Sepharose $6 \mathrm{~B}$, a partir de músculo do peixe "medaka" Oryzias latipes e glândulas submandibulares de rato, Rattus novegicus albino, respectivamente. SASAKI et al., (1989), obtiveram purificação de 82 vezes para LDH-A 4 e 117 vezes para $\mathrm{LDH}_{-} \mathrm{B}_{4}$ com recuperação de 3,36 e 13\% para ${\mathrm{LDH}-\mathrm{A}_{4} \text { e LDH-B }}_{4}$, respectivamente; SASSAKI et al., (1994), obtiveram uma purificação de 26,8 vezes e recuperação de $26 \%$, outro experimento descrito na literatura por JAVED et al., em 1995 utilizando cromatografia em colchicina-sepharose e inativação pelo calor a $80^{\circ} \mathrm{C}$ durante 30 minutos, purificaram a LDH-1 do fígado de Uromastix hardwickii obtendo uma recuperação de 17,38\% e um fator de purificação de 17,23 vezes.

Nossos resultados de purificação e recuperação obtidos partindo-se do extrato bruto de músculo esquelético branco de Prochilodus scropha e Notothenia neglecta podem ser considerados satisfatórios, o que vem a confirmar a especificidade da resina oxamato-agarose para a purificação da LDH, embora a fração purificada, para ambas as espécies, tenha se apresentado instável, perdendo cerca de $10-15 \%$ da atividade por dia. A fração purificada da resina oxamatoagarose foi mantida em tampão fosfato $0,1 \mathrm{M}, \mathrm{pH}$ 7,4 , a $4^{0} \mathrm{C}$, contendo glicerol $20 \%$. Esta preparação manteve atividade constante por aproximadamente 2 meses.

A diferença na inibição do substrato tem sido sugerida como a base para se distinguir o desempenho fisiológico para isoenzimas de $\mathrm{LDH}$ da maioria dos vertebrados. A LDH tipo $\mathrm{H}$ tem atividade máxima em baixas concentrações de piruvato sendo fortemente inibida em altas concentrações. O tipo $\mathrm{M}$ mantém sua atividade em altas concentrações de piruvato. A inibição da LDH do coração pelo piruvato favorece a completa oxidação de piruvato e lactato pela via oxidativa na mitocôndria, enquanto a LDH do músculo esquelético permite o suprimento rápido de energia via glicólise, convertendo as grandes quantidades de piruvato que se formam em lactato liberando-o para o sangue, o qual deve ser usado como fonte de energia pelo coração principalmente durante exercícios vigorosos, hipóxia ou durante a sua recuperação (DAWSON et al., 1964; MENDIOLA e DE COSTA, 1991). O mecanismo proposto para inibição da LDH pelo piruvato é a formação do

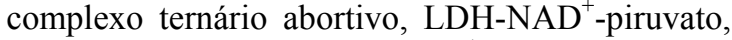
resultando na interação do $\mathrm{NAD}^{+}$com o piruvato e a enzima. A oxidação do $\mathrm{NADH}+\mathrm{H}^{+}$para $\mathrm{NAD}^{+}$ durante a redução catalisada pela $\mathrm{LDH}$ de piruvato para lactato resulta na formação do complexo ternário. Este complexo inibe competitivamente a redução de piruvato pelo $\mathrm{NADH}+\mathrm{H}^{+}$. A constante de dissociação para o complexo ternário da $\mathrm{LDH}$ do músculo cardíaco é menor do que para a $\mathrm{LDH}$ do músculo esquelético, com o resultado de que a LDH do coração é inibida em condições fisiológicas enquanto que a forma muscular esquelética tem significativa atividade. FITCH (1988), que determinou a atividade máxima para o músculo esquelético de Notothenia neglecta em 2,5 $\mathrm{mM}$ de piruvato e SASAKI et al., (1989), com músculo esquelético branco de Oryzias latipes determinaram o $\mathrm{Km}$ para piruvato em 0,62 $\mathrm{mM}$.

Lactato desidrogenase da maioria dos peixes é composta de 3 subunidades polipeptídicas distintas, LDH-A, LDH-B E LDH-C, as quais têm sido estabelecidas através de estudos genéticos, bioquímicos e imunológicos. Enquanto as subunidades A e B exibem uma ampla distribuição nos tecidos, a subunidade $\mathrm{C}$ contém isoenzimas que são restritas a tecidos neurais ou digestivos, predominantemente no fígado e do globo ocular (REHSE e DAVIDSON, 1985; FRANKEL, 1987; FITCH, 1988, COPPES et al., 1992).

As formas moleculares de $\mathrm{LDH}$ foram separadas primeiramente por eletroforese onde se observam geralmente 5 bandas (ou formas) sendo 2 referentes a formas parentais e 3 formas híbridas, todas tetraméricas. As formas parentais foram denominadas de $\mathrm{H}$ e $\mathrm{M}$ de acordo com a predominância de cada uma no coração e no músculo, respectivamente. $\mathrm{O}$ tipo $\mathrm{H}$ é composto de 4 subunidades $\mathrm{H}\left(\mathrm{H}_{4}\right)$ e o tipo $\mathrm{M}$ de quatro subunidades $\mathrm{M}\left(\mathrm{M}_{4}\right)$, enquanto as 3 formas de $\mathrm{LDH}$ são híbridos moleculares consistindo de misturas das subunidades: $\mathrm{M}_{3} \mathrm{H}, \mathrm{M}_{2} \mathrm{H}_{2}$ e $\mathrm{MH}_{3}$. A LDH do tipo $\mathrm{H}$ é abundante em tecidos com metabolismo predominantemente aeróbico, enquanto em tecidos anaeróbicos prevalece a enzima tipo $\mathrm{M}$.

As isoenzimas da LDH podem ser visualizadas submetendo-se uma amostra à eletroforese, em $\mathrm{pH}$ 8,6 . Neste $\mathrm{pH}$, as isoenzimas possuem cargas diferentes e migram para cinco regiões distintas na eletroforese, que são localizadas pela sua capacidade de catalisar a redução de um corante incolor à sua forma corada e insolúvel. A isoenzima $\mathrm{H}_{4}$ é também chamada LDH1 e na eletroforese tem maior mobilidade em direção ao ânodo. A isoenzima M4 é também chamada LDH5 e corresponde à banda mais próxima do cátodo. Os híbridos são denominados LDH2 $\left(\mathrm{MH}_{3}\right)$, LDH3 $\left(\mathrm{M}_{2} \mathrm{H}_{2}\right)$ e LDH4 $\left(\mathrm{M}_{3} \mathrm{H}\right)$. 
Os homogeneizados dos músculos esqueléticos de Prochilodus scropha e de Notothenia neglecta, quando aplicados em fita de acetato de celulose apresentaram perfil eletroforético característico para estes tecidos, revelando a presença de uma única isoenzima correspondente ao tipo $\mathrm{M}_{4}\left(\mathrm{~A}_{4}\right)$. A LDH-4 do músculo de Notothenia neglecta migra para o ânodo e a LDH-4 do músculo de Prochilodus scropha migra para o cátodo. Este resultado confirma o encontrado em Prochilodus scropha por FENERICH-VERANI et al. (1990). Estes autores analisaram tecidos de Prochilodus scropha em diferentes estágios de desenvolvimento embriológico mostrando que a $\mathrm{LDH}_{-} \mathrm{B}_{4}$ esteve presente durante todo o estágio embriológico desta espécie e se expressou em todos os tecidos analisados, e que a $\mathrm{LDH}_{-} \mathrm{A}_{4}$ expressou-se, predominantemente, no músculo esquelético branco e foi primeiramente detectada quando a larva mostrou sinais acentuados de natação, onde esta enzima tem um importante papel no metabolismo analítico e a geração de ATP.

Segundo SIDELL e BELAND (1980) e TSUJI et al. (1994), isoenzima de LDH foi primeiramente identificada em um único locus como LDH tipo A e este locus, no processo da evolução, foi duplicado para formar os loci da LDH-A e LDH-B, sendo que o locus LDH-B foi duplicado para formar os loci da LDH-B e LDH-C. Esta hipótese tem persistido até agora, uma vez que em Agnatha (lampréias) foi identificada uma única isoenzima $\mathrm{LDH}$ do tipo $\mathrm{A}_{4}$.

A presença de isoenzimas com diferentes propriedades em diferentes temperaturas é um fato que ocorre durante a aclimatação a temperaturas altas e baixas para a manutenção de características enzimáticas, como o $\mathrm{K}_{\mathrm{M}}$. Enquanto caracteres morfológicos e ecológicos são similares entre Notothenia neglecta e Prochilodus scropha, dissimilaridades surgem em um nível bioquímico, possivelmente em resposta a diferentes temperaturas impostas para cada espécie.

A isoenzima $\mathrm{LDH}_{-} \mathrm{M}_{4}$ ocorre em maior concentração no músculo esquelético branco. Este tecido geralmente é pobre no suprimento de sangue, apresenta capacidade reduzida para oxidar piruvato, e uma grande fração de energia para a contração é obtida da glicólise anaeróbica. Consequentemente, a conversão do piruvato para lactato é de maior importância para este tecido do que para a musculatura vermelha. Segundo BALDWIN (1975), o nível da atividade total de enzimas nos tecidos pode ser ajustado por mudanças na eficiência catalítica bem como por alteração na quantidade da enzima, a qual deve ser sustentada como uma vantagem adaptativa para espécies que dependem de um grau maior de glicólise anaeróbica.

Espécies antárticas são especializadas a condições de frio. Mudanças sazonais na temperatura são menores do que $0,2^{0} \mathrm{C}$, organismos adaptados a baixas temperaturas apresentam taxa metabólica de descanso alta. Parte do metabolismo de descanso elevado de espécies antárticas deve ser devido à manutenção de um sistema nervoso e de um sistema sensorial eficientes, à síntese de proteínas anticongelantes e à atividade fisiológica. Durante a evolução estes organismos tiveram que compensar a ausência de bexiga natatória incorporando lipídeos, reduzindo a densidade e envolvendo adaptações hidrodinâmicas para flutuações. $\mathrm{Na}$ ausência de mecanismos compensatórios, os processos fisiológicos devem proceder mais lentamente nestas espécies do que provavelmente em espécies tropicais.

\section{REFERÊNCIAS BIBLIOGRÁFICAS}

BACILA, M.; ROSA, R.; RODRIGUES, E.; LUCHIARI, P.H.; ROSA, C.D. Tissue metabolism of the ice-fish Chaenocephalus aceratus Loenberg. Comp. Biochem. Physiol. 92B(2):313-318, 1989.

BAILEY, G.S.; WILSON, A.C. Homologies between isoenzymes of fishes and those of higher vertebrates. J. Biol. Chem. 243(22):5843-5853, 1968.

BALDWIN, J. Selection for catalytic efficienty of lactate dehydrogenase M4: correlation with body temperature and levels of anaerobic glycolysis. Comp. Biochem. Physiol. 52B:33-37, 1975.

BARNETT, H. Electrophoretic separation of lactate dehydrogenase isoenzymes on cellulose acetate. Biochem. J. 84:83, 1962.

BERGMEYER, H.V.; BERN, T.E. Lactate desidrogenase U.V. assay with pyruvate kinase and LDH. In "Bergmeyer H.V., Ed. Methods of enzymatic analysis. $2^{\text {nd }}$ ed. New York, Verlag-Chemie, 1974.

CARVALHO, C.S. Purificação, caracterísitcas cinéticas e isoenzimas da lactato desidrogenase (L-lactato $\mathrm{NAD}^{+}$ oxidorreductase, E.C.1.1.1.27) do músculo epaxial de curimbatá Prochilodus scrofa (Steidachner, 1881) e de Notothenia neglecta (Pisces, Teleostei). Tese de Mestrado em Fisiopatologia e Comportamento de Organismos Aquáticos, UFPR, 1997.

COPPES, Z. Lactate dehydrogenase in teleosts. The role of LDH-C4 isozyme. Comp. Biochem. Physiol. 102B(4):673-677, 1992.

COPPES, Z.; MARTÍNEZ, G.; HIRSCHHORN, M. pH and temperature effects on the $\mathrm{Km}$ values of muscle lactate dehydrogenase isozyme $\mathrm{LDH}-\mathrm{A}_{4}$ from fishes of the family Scianidae (Perciformes); Comp. Biochem. Physiol. 103B(4):869-874, 1992.

DAWSON, D.M.; GOODFRIEND, T.L.; KAPLAN, N.O. Lactic dehydrogenases: functions of the two types. Rates of synthesis of the two major forms can be correlated with metabolic differentiation. Science. 207:769-770, 1964.

DE WITT, H.H. Coastal and deep-water benthic fishes of the Antarctic. Am. Geogr. Soc. Antarct. Map Folio Ser. 15:1-10, 1971.

ELLINGTON, W.R.; LONG, G.L. Purification and characterization of a highly unusual tetrameric Dlactate dehydrogenase from the muscle of the giant barnacle, Balanus nubilus Darwin. Arch. Biochem. Biophys. 186 2:265-274, 1978. 
FELLER, G.; PAULY, J.P.; O'CARRA, P.; GERDAY, C. The lactate dehydrogenase of the icefish heart: biochemical adaptations to hypoxia tolerance. Biochim. Biophys. Acta. 1079 3:343$347,1991$.

FENERICH-VERANI， N.; SCHWANTES， M.L.B.; SCHWANTES, A.R. Patterns of gene expression during Prochilodus scrofa (Characiformes: Prochilontidae) embryogenesis - I. Lactate dehydrogenase. Comp. Biochem. Physiol. 97B(2):235-246, 1990.

FITCH, N.A. Lactate dehydrogenases in Antarctic and temperate fish species. Comp. Biochem. Physiol. 91B(4):671-676, 1988.

FRANKEL, J.S. Lactate dehydrogenase isozymes of the island barb, Barbus oligolepis (Cypriniformes, Teleostei): their characterization and ontogeny. Comp. Biochem. Physiol. 87B(3):581-585, 1987.

GADE, G. Lactate specific dimeric lactate dehydrogenase from the mantle muscle of the squid, Loligo vulgaris: purification and catalytic properties. Comp. Biochem. Physiol. 63B: 387-393, 1979.

HECK, H. d'A. Porcine heart lactate dehydrogenase optical rotatory dispersion, thermodynamics, and kinetics of binding reactions. J. Biol. Chem. 244:4375-4381, 1969.

JAVED, M.H.; YOUSUF, F.A.; HUSSAIN, A.N.; ISHAQ, M.; WAQAR, M.A. Purification and properties of lactate dehydrogenase from liver of Uromastix hardwickii. Comp. Biochem. Physiol. 111B(1):27-34, 1995.

LOW, P.; SOMERO, G. Adaptation of muscle pyruvate kinase to environmental temperatures and pressures. J. Exp. Zoll. 198:1-11, 1976.

LOWRY, D.R.; ROSEBROUGH, N.J.; FARR, A.L.; RANDALL, R.J. Protein measurement with the Folin phenol reagent. J. Biol. Chem. 193:265-275, 1951.

MENDIOLA, P.; DE COSTA, J. The effects of temperature and $\mathrm{pH}$ on the kinetic properties of heart muscle lactate dehydrogenase from anuran amphibians. Comp. Biochem. Physiol. 98B(4):529534, 1991.

O'CARRA, P.; BARRY, S. Affinity cromatography of lactate dehydrogenase. FEBS Lett. 21:281-285, 1972.

O'CARRA, P.; BARRY, S. Lactate dehydrogenase specific ligand approach. Methods Enzymol. 34:598-605, 1974.

REHSE, P.H.; DAVIDSON, W.S. Purification and properties of a C-type isozyme of lactate dehydrogenase from the liver of the Atlantic cod (Gadus morhua). Comp. Biochem. Physiol. 84B:145-150, 1985.

SASAKI, T.; HYODO-TAGUCHI, Y.; IUCHI, I.; YAMAGAMI, K. Purification and partial characterization of the muscle LDH-A4 and -B4 isozymes and the respective subunits of the fish, Oryzias latipes. Comp. Biochem. Physiol. 93B(1):11-20, 1989.
SASSAKI, K.T.; ROSA, C.D.; CERQUEIRA CÉSAR, M.; ROSA, R.; Kinectic aspects of rat (Rattus norvegicus albinus) submandibular glands lactic dehydrogenase. Arq. Biol. Tecnol. 37, 2:333-343, 1994.

SCOPES, R.K.; Quantitative studies of ion-exchange and affinity elution chromatography of enzymes. Anal. Biochem. 114:8-18, 1981.

SIDELL, B.D.; BELAND, K.F.; Lactate dehydrogenase of Atlantic hagfish: Physiological and evolutionary implications of a primitive heart isozyme.Science. 207:769-770, 1980.

SOMERO, G. N.; HOCHACHKA, P.W. The effect of temperature on catalytic and regulatory functions of pyruvate kinase of the rainbow trout and the Antarctic fish Trematomus bernachii. Biochem. J. 110:395-400, 1968.

SPIELMANN, H.; ERICKSON, R.P.; EPSTEIN, C.J. The separation of lactate dehydrogenase $\mathrm{x}$ from other lactate dehydrogenase isozymes of mouse testes by affinity chromatography. FEBS Lett. 35, 1:19-23, 1973.

STRAUB, F.B.; Crystalline lactic dehydrogenase from heart muscle. Biochem. J. 34:483-486, 1940.

THÉBAULT, M.T.; BERNICARD, A.; LENNON, J.F. Lactate dehydrogenase from the caudal muscle of the shrimp Palaemon serratus: Purification and characterization. Comp. Biochem. Physiol. 68B:6570, 1981.

TSUJI, S.; QURESHI, M.A.;HOU, E.W.; FITCH, W.M.; LI, S.S.L. Evolutionary relationships of lactate dehydrogenases (LDHs) from mammals, birds, an amphibian, fish, barley, and bacteria: LDH cDNA sequences from Xenopus, pig, and rat. Proc. Natl. Acad. SCI. 91:9392-9396, 1994.

VESELL, E.S. pH Dependence of lactate dehydrogenase isozyme inhibition by substrate. Nature. 5034 23:421-422, 1966.

VESELL, E.S.; YIELDING, L. Effects of $\mathrm{pH}$, ionic strenghth, and metabolic intermediates on the rates of heat inactivation of lactate dehydrogenase isozymes. Proc. N.A.S. 56:1317-1324, 1966.

ZAMORA, J.M.; ROSA, R.; ROSA, C.D.; BIANCONCINI, M.S.C.; BACILA, M. Purification and properties of pyruvate kinase from the striated muscle of the ice-fish Chaenocephalus aceratus Loenberg.; Int. J. Biochem. 24, 11:1833-1840, 1992.

ZIETARA, M.S.; SKORKOWSKI, E.F.; Purification and properties of the heart type lactate dehydrogenase of the cod (Gadus morhua) from the Baltic sea: comparison with LDH-A4 e LDH-C4. Comp. Biochem. Physiol. 105B:349-356, 1993. 